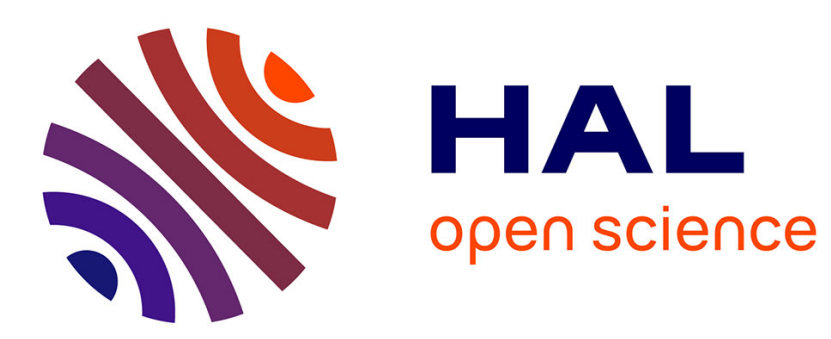

\title{
Risk management activities of a non-industrial private forest owner with a bivariate utility function
}

\author{
Marielle Brunette, Stéphane Couture
}

\section{To cite this version:}

Marielle Brunette, Stéphane Couture. Risk management activities of a non-industrial private forest owner with a bivariate utility function. Review of Agricultural, Food and Environmental Studies, 2018, 99 (3), 302 p. 10.1007/s41130-018-0081-x . hal-01969242

\section{HAL Id: hal-01969242 \\ https://hal.science/hal-01969242}

Submitted on 16 Dec 2020

HAL is a multi-disciplinary open access archive for the deposit and dissemination of scientific research documents, whether they are published or not. The documents may come from teaching and research institutions in France or abroad, or from public or private research centers.
L'archive ouverte pluridisciplinaire HAL, est destinée au dépôt et à la diffusion de documents scientifiques de niveau recherche, publiés ou non, émanant des établissements d'enseignement et de recherche français ou étrangers, des laboratoires publics ou privés. 


\title{
Risk management activities of a non-industrial private forest owner with a bivariate utility function
}

\author{
Marielle Brunette $^{1}$ (D) . Stéphane Couture ${ }^{2}$
}

Received: 20 June 2017 / Accepted: 5 November 2018 / Published online: 26 November 2018 (C) INRA and Springer-Verlag France SAS, part of Springer Nature 2018

\begin{abstract}
We analyze the insurance and self-insurance choices of a private forest owner whose utility is bivariate (consumption and forest amenity value). We show that under fair premium, full insurance is optimal only if the cross derivative of the utility function is equal to zero, whereas under unfair premium, optimal partial insurance is validated only if the cross derivative is positive. We also show that insurance and self-insurance may be substitutes, and if preferences are separable and the cost of insurance is not so high, then insurance and self-insurance are always considered as substitutes. However, we find in an illustration with a non-separable bivariate utility function, characterized by weights given to consumption and amenities, that insurance and self-insurance are complement. We obtain that the weight given to amenities substantially affects optimal risk management activities for unfair insurance. These results highlight the importance to represent the forest owner's behavior through a bivariate utility function.
\end{abstract}

Keywords Bivariate utility - Cross derivative · Forest management · Insurance · Risk - Self-insurance

\section{Introduction}

Many works on forest economics concentrated on the behaviors of non-industrial private forest (NIPF) owners, mainly focusing on the harvesting decision from the point

Marielle Brunette

marielle.brunette@inra.fr

Stéphane Couture

stephane.couture@inra.fr

1 BETA, Université de Lorraine, Université de Strasbourg, AgroParisTech, CNRS, INRA, 54000, Nancy, France

2 MIAT, Université de Toulouse, INRA, Castanet-Tolosan, France 
of view of timber production and the market. This emphasis on harvesting as the primary utility derived from consumption due to revenue from forest production may constitute an incomplete description of forest owners' behaviors. Indeed, some forest owners may be less interested in purely market-based activities and more interested in participating in non-timber activities on their land, such as, for example, hiking, landscape contemplation, and wildlife observation. Thus, some NIPF owners may have a positive utility due to the amenity functions of their forests, produced jointly with timber and vanishing with the standing stock, along with the revenue from timber sales. The NIPF owners confer private values on the amenity services of their forest stock, even if there are no financial incentives linked to these functions (Zhang et al. 2005). More precisely, NIPF owners place a higher value on their standing timber and forestland than industrial forest owners because of amenity preferences (Newman and Wear 1993). Therefore, non-timber activities could be important in determining whether a forest owner harvests or not, as well as how s/he manages risk. Indeed, NIPF owners face natural risks that directly affect timber production and the amenity services to be obtained from standing stock (Schelhaas et al. 2003). Amenities therefore reinforce the interest of risk management measures. In such a context, the risk preferences of forest owners are determinants (Andersson and Gong 2010; Brunette et al. 2013). Risk aversion is always a feature of optimal forest management. In particular, risk preferences strongly affect some forest management decisions such as rotation length or planting, as well as other decisions linked to forest activities such as forest investments (Kangas 1994) or probability to harvest (Brunette et al. 2017).

Forest risk management strategies can be divided into two main categories: those that involve risk sharing and those that do not. The main risk sharing strategy to be considered is insurance. Indeed, in several countries, insurance contracts against fire and/or storm are proposed to NIPF owners (Holecy and Hanewinkel 2006; Brunette and Couture 2008a; Manley and Watt 2009). Risk management strategies that do not involve risk sharing are common in forestry and are numerous. The simplest and most basic actions that can be implemented to face risks are those reducing the damage that a given hazard would cause. Such actions are referred to as self-insurance activities by economists (Ehrlich and Becker 1972). These activities are designed to mitigate the risks that impinge upon optimal forest management. There are some very typical risk management strategies such as, for example, internal fire tracks, reduction of rotation length, use of fencing and other natural barriers around forest edges (Manley and Watt 2009), and control burning (Amacher et al. 2009). In practice, it is unusual for forest owners to implement both types of risk management. This behavior is explained by a theoretical model proposed in a more general context by Ehrlich and Becker (1972), which shows that insurance and self-insurance act as substitutes. Moreover, amenities may also have an impact on these risk management strategies. For example, Brunette and Couture (2013) find that the larger the marginal utility of amenities is, the larger the physical and financial savings would be, but they consider that the utility of amenity is separable from the utility of production. Consequently, several questions arise: How does the introduction of amenities into the utility function, in addition to utility from consumption, affect the optimal decision of risk management activities? Do self-insurance and insurance act as 
substitutes when amenities are taken into account? What is the role of risk preferences on risk management decisions with a bivariate utility function?

There is evidence in the forest economics literature that the introduction of amenity services into the forest management analysis has an impact on numerous decisions such as optimal harvesting age (Hartman 1976; Max and Lehman 1988), forest management and stand structure (Pattanayak et al. 2002), and investment (Zhang et al. 2005). Moreover, the effects of risk and amenity preferences on timber supply are previously and jointly analyzed in the rotation model (Englin et al. 2000) and in the two-period model (Amacher et al. 2009; Brunette and Couture 2013). These studies obtain that the harvesting rule is defined by a tradeoff between harvesting revenue and amenity value. However, these papers do not address NIPF owners' insurance behavior and, as a consequence, do not deal with a potential substitutability/complementarity between insurance and self-insurance. More importantly, a main assumption in these papers, but also more generally in forest economics (Koskela and Ollikainen 1997), is that utility can be separated into timber and non-timber components. The use of a bivariate utility function has thus, to our knowledge, never been considered in this literature. We take these two points in turn.

First, insurance decisions are the subject of a large literature since the early works of Arrow (1963) and Mossin (1968). The main conclusion of these papers is that a risk-averse agent who maximizes his or her expected utility of wealth chooses full insurance if the insurance premium displays no loading factor (fair premium), and partial insurance otherwise (Arrow 1963; Mossin 1968). In addition, Ehrlich and Becker (1972) prove that insurance and self-insurance are substitutes. These results are validated in a forestry framework with a univariate utility function (Brunette and Couture 2008a, b).

Second, the multivariate utility function appeared for the first time in Eisner and Strotz (1961) with pecuniary assets as arguments. The idea to consider a nonpecuniary asset as an argument in a bivariate utility function appeared at the end of the 1970s with the literature on "irreplacable commodities" such as family snapshots, the family pet, good health, the life of a beloved spouse or child, etc., i.e., commodities that have a non-pecuniary value for their owners in addition to market value (Cook and Graham 1977). The seminal paper of Cook and Graham (1977) was the beginning of a long series of articles on this topic (Schlesinger 1984; Huang and Tzeng 2006). This bivariate utility function is then applied to various economic fields such as health economics where it is widely used (Rey 2003; Eeckhoudt et al. 2007; Etner and Spaeter 2012; Tabo 2013). The behavior of an individual in terms of preventive measures to protect his or her health has been considerably studied using a two-dimensional utility (Tabo 2013). This literature principally concentrates on the analysis of the link between curative measure and primary (as self-protection) and secondary (as self-insurance) preventions. This literature highlights that the cross derivative of the bivariate utility function (i.e., the variation of the marginal utility of wealth with respect to the non-pecuniary variable) plays a significant role. In the same way, the paper of Denuit et al. (2011) studied, in a generic analysis, the optimal investment decision within a two-period bivariate utility model. The link between the optimal choices and the direct and cross derivatives of the bivariate utility function is also analyzed. 
To our knowledge, such a bivariate utility function has been very few applied to forest economics to analyze utility derived from timber and non-timber benefits (see Amacher et al. (2018) for an exception) and to study risk management activities (market insurance and self-insurance practices) of a forest owner considering the specificities of the forest such as a forest damage depending on the value of the stand (Brunette and Couture 2008a, b).

Consequently, our objective is to analyze the NIPF owner's insurance and selfinsurance decisions considering a bivariate utility function. We propose a static analytical model of decision under risk, taking risk preferences into account. First, we separately analyze insurance and self-insurance decisions in order to test the validity of the existing results in our particular framework. We then analyze optimal insurance with self-insurance activities. Finally, we apply the model to data for a representative NIPF owner located in Southwestern France.

The rest of the paper is organized as follows. The "Hypothesis of the model" section presents the hypothesis of the model. The "A separate analysis of optimal insurance and self-insurance" section describes the optimal insurance decision and determines the optimal self-insurance behavior, independently one from another. The "Optimal insurance with self-insurance activity" section deals with the optimal insurance when the NIPF owner may also self-insure. The "Illustration" section proposes an illustration of the theoretical model. Finally, the results are discussed in the "Discussion" section and the "Conclusion" section provides a conclusion.

\section{Hypothesis of the model}

We consider a static model in which a NIPF owner derives utility from consumption and from the amenity value of the forest. This amenity value includes various nonpecuniary values linked to the existence and the volume of the forest stand (Max and Lehman 1988) and providing utility to the NIPF owner, such as having inherited the forest from a close relative, or the simple act of walking in the forest or picking mushrooms or berries. The forest owner's preferences are described by a bivariate utility function $U(C, M)$ where $C$ is the consumption and $M$ the amenity value of the forest. $U$ is increasing and concave in each term ${ }^{1} U_{1}>0, U_{11}<0, U_{2}>0$, $U_{22}<0$, representing a risk-averse NIPF owner. We do not impose restriction on $U_{12}$, i.e., on how the amenity value of the forest varies with the marginal utility of consumption.

The consumption of the forest owner directly depends on the revenue from harvesting. We assume that the forest owner possesses an even-aged forest that provides an optimal revenue $R$ corresponding to the commercial value of a timber stand at the optimal cut period. This revenue is subject to natural risks and, therefore, to a possible loss. This risk appears with a probability $p$, and the loss is a proportion of the revenue: $L=x R$, with $x$ in $[0,1]$. This assumption of a loss that depends on the forest value is particularly well adapted in our model, as underlined by Brunette

\footnotetext{
${ }^{1}$ Index $i$ denotes a partial derivative of the utility function with respect to argument $i$ ( $i=1$ or 2$)$.
} 
and Couture (2008a, b), whereas, traditionally in the economics literature, insurance and self-insurance decisions are analyzed in view of an exogenous loss (Schlesinger 2000; Eeckhoudt et al. 2005). However, in the case of forestry, when a natural hazard occurs, the NIPF owner's associated loss is proportional to the forest value. Risk also affects the amenity value of the forest. Indeed, if the risk occurs, the impact will also be felt on non-timber benefits; the loss for this component is $h$.

In order to address such a risk, the forest owner can purchase a co-insurance policy. This insurance contract consists of an indemnity function where the private forest owner receives a payment $\alpha L$ in the event of a loss $L$, as well as a premium $P$, which must be paid regardless of what occurs. The forest owner chooses $\alpha$ between 0 and 1 , where $\alpha=0$ in the absence of insurance, and $\alpha=1$ in the case of full insurance. The premium for the given indemnity function takes the form $P(R)=$ $(1+\lambda) \alpha \mu(R)$ where $\mu(R)=E[L]=p x R, \lambda \geq 0$ is the loading factor and $E$ is the expectation operator. We assume that there is no moral hazard problem, implying that the forest owner will not be more careless when managing his or her forest as a result of purchasing insurance. Furthermore, we assume that the insurer has the same information about risk as the forest owner, implying that there will be no adverse selection issue.

In addition to the insurance decision, forest owners may also implement selfinsurance activities such as clearing, in order to reduce the damage in the case of fire risk occurrence. We assume that self-insurance is observable by the insurer and is taken into account when the premium is computed ${ }^{2}$, so that the premium and the indemnity are written as follows: $P=(1+\lambda) \alpha p x(q) R$ and $I=\alpha x(q) R$, where $q$ denotes the self-insurance activity. Self-insurance activities are costly; $c_{S I} q$ denotes the cost of these practices with $c_{S I}$ the unit cost of self-insurance. Self-insurance activity $q$ affects the loss $x$ through $x(q)$, where $x_{q}<0$ and $x_{q q}>0$.

Our framework is close to the bivariate utility model proposed by Rey (2003) to analyze the optimal insurance in the presence of non-pecuniary background risk, but differs in three points. First, the model of Rey (2003) considers two types of risks-insurable financial risk and non-pecuniary uninsurable risk-but these risks are independent. This assumption is not realistic in the case of forest management. Second, the financial loss is independent of the revenue, which is not a correct assumption in the case of forest damage. Finally, Rey (2003) does not consider the problem of self-insurance, and then does not deal with the substitutability issue.

The forest owner's expected utility is written as follows:

$$
\begin{aligned}
V(\alpha, q)= & p U\left(R-x(q) R+\alpha x(q) R-(1+\lambda) \alpha p x(q) R-c_{S I} q, M-h\right) \\
& +(1-p) U\left(R-(1+\lambda) \alpha p x(q) R-c_{S I} q, M\right)
\end{aligned}
$$

In order to analyze the optimal decisions of risk management, we analyze each tool separately and, then, we study the optimal insurance decision when the forest owner can also adopt self-insurance.

\footnotetext{
${ }^{2}$ When a forest owner wants to take out forest insurance, an expert from the insurance company visits the forest property to ascertain that the information provided by the owner is correct. The expert can then easily observe if the owner implements self-insurance activities or not.
} 


\section{A separate analysis of optimal insurance and self-insurance}

First, we analyze the optimal insurance decision without self-insurance and second, the optimal self-insurance decision without insurance.

\section{Optimal insurance decision}

In this section, we deal with the optimal insurance decision without self-insurance. In this case, the private forest owner has to choose $\alpha$ to maximize his or her expected utility:

$$
\begin{aligned}
\operatorname{Max}_{\{\alpha\}} V(\alpha)= & p U(R-x R+\alpha x R-(1+\lambda) \alpha p x R, M-h) \\
& +(1-p) U(R-(1+\lambda) \alpha p x R, M)
\end{aligned}
$$

In insurance economics, it is a common practice to consider two situations regarding the insurance premium; either a fair insurance premium when the loading factor is nil or an unfair one when the loading factor is positive.

\section{Fair insurance premium}

In case of a fair insurance premium $(\lambda=0)$, then the forest owner's maximization program is as follows:

$$
\operatorname{Max}_{\{\alpha\}} U(\alpha)=p U(R-x R+\alpha x R-\alpha p x R, M-h)+(1-p) U(R-\alpha p x R, M)
$$

The first-order condition is:

$$
\begin{aligned}
\frac{d U(\alpha)}{d \alpha}= & p U_{1}(R-x R+\alpha x R-\alpha p x R, M-h)(x R(1-p)) \\
& -(1-p) U_{1}(R-\alpha p x R, M)(p x R)=0
\end{aligned}
$$

Our assumptions ensure that the second-order conditions are verified. The optimal insurance decision is defined in such a way that the marginal cost of insurance is equal to its marginal benefit in terms of utility.

We evaluate this first-order condition for full insurance $(\alpha=1)$. The sign of the condition depends on the sign of the cross derivative $U_{12}$, as explained in Proposition 1 (see Appendix 1 for the proof).

Proposition 1 In case of a fair insurance premium, the optimal insurance level depends on the sign of $U_{12}$ :

- If $U_{12}<0$, then the forest owner prefers over-insurance.

- If $U_{12}=0$, then the forest owner prefers full insurance.

- If $U_{12}>0$, then the forest owner prefers under-insurance.

With a univariate utility function, if insurance is available at a fair price, then full insurance is optimal (Schlesinger 2000). This widely recognized result is based on the Bernoulli principle, which holds that risk-averse agents choose to fully insure when the insurance premium is actuarially fair. With a bivariate utility function that depends on consumption and the amenity value of the forest, this conclusion is 
only true if $U_{12}=0$, i.e., when the marginal utility of consumption is a constant function of the amenity value of the forest. In addition, under-insurance and overinsurance may also be optimal decisions, depending on the sign of the cross derivative of the utility function $U_{12}$. When $U_{12}<0$, i.e., the amenity value decreases with the marginal utility of consumption, a risk-averse forest owner will always prefer to insure at a level higher than full insurance in order to guarantee the total damage due to the risky event. Contrary, when $U_{12}>0$, a forest owner will prefer a partial insurance. The sign of the cross derivative $U_{12}$ indicates the attitudes of the forest owner towards correlation; $U_{12}>0$ corresponds to a correlation-averse agent while $U_{12}<0(=0)$ corresponds to a correlation-affine (correlation-neutral) agent (Epstein and Tanny 1980).

These results are in line with the previous conclusions obtained in Rey (2003). Indeed, she examined the optimal insurance demand considering a bivariate utility function (wealth and non-pecuniary asset as arguments). She highlighted the important role of the sign of the variation of the marginal utility of wealth with respect to the non-pecuniary asset. She also found the conditions for which the Bernoulli principle holds. In our framework, we find the same conditions.

\section{Unfair insurance premium}

We now examine the forest owner's optimal insurance demand when the insurance premium is unfair $(\lambda>0)$. With a univariate utility function, the optimum for the decision maker is to retain some risk and to opt for partial insurance coverage. This widely recognized result, known as the Mossin-Smith proposition (Mossin 1968; Smith 1968), states that full insurance is suboptimal when the premium is unfair. When the forest owner derives utility from his or her consumption and the amenity value of the forest, the optimal insurance level solves the problem defined by Eq. (2).

The optimal level of co-insurance, $\alpha^{*}$, satisfies:

$$
\begin{aligned}
\frac{d V(\alpha)}{d \alpha}= & \left.p U_{1}\left(R-x R+\alpha^{*} x R-(1+\lambda) \alpha^{*} p x R, M-h\right)(x R-(1+\lambda) p x R)\right) \\
& -(1-p) U_{1}\left(R-(1+\lambda) \alpha^{*} p x R, M\right)((1+\lambda) p x R)=0
\end{aligned}
$$

Our assumptions ensure that the second-order conditions are verified.

We evaluate this first-order condition for full insurance $(\alpha=1)$. We observe that the sign of the condition depends on a threshold value for the loading factor $\lambda_{0}$, as described in Proposition 2 (see Appendix 2 for the proof).

Proposition 2 In case of unfair insurance premium, if $U_{12} \leq 0$ and $\lambda \leq \lambda_{0}$ where $\lambda_{0}>0$, full insurance is optimal. If $U_{12}>0$, full insurance is never optimal.

Consequently, the Mossin-Smith proposition holds for $U_{12}$ positive. Otherwise, full insurance may be optimal. The forest owner may choose full insurance even if the insurance premium is unfair. The determinants of the demand for insurance depend not only on the shape of the insurance premium but also on how the marginal utility of consumption varies with the amenity value of the forest. These results highlight the importance of the sign of $U_{12}$. 
This conclusion was previously obtained by Rey (2003). She also proved the importance of the level of the loading factor. For a sufficiently large loading factor, the Mossin-Smith proposition holds in the sense that "less than full coverage is optimal when the premium is loaded" (Rey 2003).

\section{Optimal self-insurance activity}

In this section, we analyze the optimal self-insurance activity without insurance, considering that $\alpha=0$. The private forest owner then has to choose the level of self-insurance activity $q$ to maximize his or her expected utility:

$$
\operatorname{Max}_{\{q\}} W(q)=p U\left(R-x(q) R-c_{S I} q, M-h\right)+(1-p) U\left(R-c_{S I} q, M\right)
$$

The optimal level of self-insurance activity, $q^{*}$, satisfies the following first-order condition:

$$
\begin{aligned}
\frac{d W(q)}{d q}= & -p U_{1}\left(R-x\left(q^{*}\right) R-c_{S I} q^{*}, M-h\right)\left(x_{q} R+c_{S I}\right) \\
& -(1-p) c_{S I} U_{1}\left(R-c_{S I} q^{*}, M\right)=0
\end{aligned}
$$

Our assumptions ensure that the second-order conditions are verified.

At the optimal self-insurance level, it is necessary that $x_{q} R+c_{S I}<0$, i.e., the potential marginal benefit must be at least as high as the cost of the increase in $q$. At the optimal level of self-insurance activity, the expected marginal benefit from the reduction in the size of a loss is equal to the expected marginal cost from the increase in self-insurance activity. This condition is quasi similar in the case of the univariate utility function (Dionne and Eeckhoudt 1985; Brunette and Couture 2008a).

\section{Comparative static results for insurance and self-insurance}

With a model of univariate decision under risk, increasing risk aversion leads the decision maker to take a lower level of risky activity (Dionne and Eeckhoudt 1985). Such a result has been proven for insurance demand, i.e., an increase in risk aversion raises insurance demand (Mossin 1968). This result is also obtained in a context of self-insurance by Dionne and Eeckhoudt (1985) who state that greater risk aversion leads to greater self-insurance. In this paper, we show that these comparative static results concerning risk aversion can be extended to a bivariate utility maximizer (see Table 1: proofs for the increase in $h$ are presented in Appendix 3 and in risk aversion in Appendix 4). Increased risk aversion always induces an increase in the optimal levels of insurance and self-insurance. The existence of an additional loss in terms of amenity value increases the interest for risk management activities in the case of a disaster. Therefore, it is interesting to analyze the effect of an increase in the loss of amenity value $h$ on the optimal insurance with fair premium and unfair premium, and optimal self-insurance. In this case, the sign of the variation of the marginal utility of consumption with respect to the amenity value of the forest plays an important role (see Table 1).

If $U_{12}<0$, an increase in the loss of the amenity value of the forest in the case of risk occurrence leads to an increase in the optimal insurance with fair and unfair 
Table 1 Comparative static results on $h$ and risk aversion

\begin{tabular}{llll}
\hline & $\begin{array}{l}\text { Optimal insurance } \\
\text { with fair premium }\end{array}$ & $\begin{array}{l}\text { Optimal insurance } \\
\text { with unfair premium }\end{array}$ & $\begin{array}{l}\text { Optimal } \\
\text { self-insurance }\end{array}$ \\
\hline$\uparrow$ in $h, U_{12}<0$ & $\alpha^{*} \uparrow$ & $\alpha^{*} \uparrow$ & $q^{*} \uparrow$ \\
$\uparrow$ in $h, U_{12}=0$ & No effect on $\alpha^{*}$ & No effect on $\alpha^{*}$ & No effect on $q^{*}$ \\
$\uparrow$ in $h, U_{12}>0$ & $\alpha^{*} \downarrow$ & $\alpha^{*} \downarrow$ & $q^{*} \downarrow$ \\
$\uparrow$ in aversion & $\alpha^{*} \uparrow$ & $\alpha^{*} \uparrow$ & $q^{*} \uparrow$ \\
\hline
\end{tabular}

premiums, as well as in optimal self-insurance. If $U_{12}=0$, then an increase in $h$ has no effect on the optima. Finally, if $U_{12}>0$, an increase in $h$ reduces the optimal fair insurance, unfair insurance, and self-insurance.

It is interesting to note that self-insurance behaves like insurance. Indeed, the comparative static results for risk aversion and loss of amenity value are identical.

\section{Optimal insurance with self-insurance activity}

In this section, we consider that the private forest owner may insure and self-insure simultaneously, i.e., $q>0$ and $\alpha>0$. The forest owner's objective will then be to maximize Eq (1).

In this case, the optimal levels of insurance and self-insurance are defined by the following first-order conditions:

$$
\begin{gathered}
\left.\frac{\partial V(\alpha, q)}{\partial \alpha}=p U_{1}\left(C_{L}, M-h\right)(x(q) R-(1+\lambda) p x(q) R)\right) \\
-(1-p) U_{1}\left(C_{N L}, M\right)((1+\lambda) p x(q) R)=0 \\
\frac{\partial V(\alpha, q)}{\partial q}=p U_{1}\left(C_{L}, M-h\right)\left(-x_{q} R+\alpha x_{q} R-(1+\lambda) \alpha p x_{q} R-c_{S I}\right) \\
-(1-p) U_{1}\left(C_{N L}, M\right)\left((1+\lambda) \alpha p x_{q} R+c_{S I}\right)=0
\end{gathered}
$$

where $C_{L}=R-x(q) R+\alpha x(q) R-(1+\lambda) \alpha p x(q) R-c_{S I} q$ is the consumption in case of loss occurrence and $C_{N L}=R-(1+\lambda) \alpha p x(q) R-c_{S I} q$ corresponds to consumption in case of no loss occurrence.

We evaluate the first-order condition (8) for full insurance $(\alpha=1)$ and we obtain:

$$
\begin{aligned}
\left.\frac{\partial V(\alpha, q)}{\partial \alpha}\right|_{\alpha=1}= & p x(q) R(1-(1+\lambda) p) U_{1}\left(\left.C_{L}\right|_{\alpha=1}, M-h\right)-p x(q) R((1+\lambda) \\
& -(1+\lambda) p) U_{1}\left(\left.C_{N L}\right|_{\alpha=1}, M\right)
\end{aligned}
$$

where $\left.C_{L}\right|_{\alpha=1}=\left.C_{N L}\right|_{\alpha=1}=R-(1+\lambda) p x(q) R-c_{S I} q$.

In the same way, evaluating the first-order condition (9) that defines optimal selfinsurance activity for full insurance allows us to observe that if $U_{12}>0$, then $q^{*}>0$, and if $U_{12} \leq 0$, then $q^{*}=0$. Consequently, $U_{12} \leq 0$ means full insurance for 
the forest owner and no self-insurance activities, whereas $U_{12}>0$ means partial insurance and a positive level of self-insurance activities.

Using the same principle as in Appendix 2, we have the following proposition:

Proposition 3 When the forest owner can simultaneously buy co-insurance and invest in self-insurance activities, full insurance is optimal if $U_{12} \leq 0$ and $\lambda \leq \lambda_{1}$ where $\lambda_{1}>0$. If $U_{12}>0$, full insurance is never optimal.

Consequently, when the forest owner can simultaneously buy co-insurance and invest in self-insurance activities, full insurance is optimal only if $U_{12}<0$. In such a case, a strictly positive scalar exists so that for any loading factor beyond this level, full insurance remains optimal. The optimal decisions of self-insurance and insurance depend on the variation of the marginal utility of wealth with respect to the nonpecuniary variable.

An investment in insurance or in self-insurance increases wealth in the bad states of nature with a cost that is the reduction of wealth in the good states. It is not surprising that self-insurance and insurance are substitutes, as was formally proven by Ehrlich and Becker (1972) in a simple model of univariate decision under risk with two states of nature. The question arises as to whether this result remains valid when considering a bivariate utility function. For this purpose, we look at the effect of an increase in the cost of insurance, through an increase in the loading factor, on the optimal self-insurance decision. In the same way, we observe the impact of an increase in the cost of self-insurance activities on the optimal insurance demand.

The substitutability between both risk management tools was also studied and proved in the health economics literature. More precisely, in health economics, it is more common to study the link between curative healthcare measures and preventive measures using a bivariate utility with the wealth and the health as arguments (see for examples Eeckhoudt et al. (1998), Eeckhoudt et al. (2007), and Tabo (2013)). Curative healthcare measures can be taken when the presence and severity of disease is known. On the contrary, preventive measures, divided into primary measures affecting the probability of disease occurrence (as self-protection), and secondary measures affecting the severity of disease (as self-insurance) can be made before knowing these two characteristics of the disease. It is found that curative and secondary preventive measures are substitutes (Eeckhoudt et al. 1998), in accordance with the fundamental conclusion of Ehrlich and Becker (1972) about the substitutability of insurance and self-insurance. In this health framework, this link is obtained in a two-period model, contrary to the static model of Ehrlich and Becker (1972), but without any explicit consideration for insurance. In our framework, unlike the health one, we simultaneously and statically examine decisions of self-insurance and insurance as in the paper of Ehrlich and Becker (1972), and we also consider the insurance decision. We find that self-insurance and insurance may be substitutes.

Our results are summarized in Proposition 4. The proof is in Appendix 5.

Proposition 4 With a bivariate utility function, the result concerning the substitution between insurance and self-insurance is ambiguous. As a consequence, the forest owner may (or not) consider insurance and self-insurance as substitutes. 
Indeed, the impact of an increase in the loading factor on the optimal self-insurance decision is ambiguous. In the same manner, the effect of an increase in the cost of self-insurance on the optimal insurance level is ambiguous, so that the two risk management strategies may (or not) be considered as substitutes by the forest owner. This conclusion differs from the existing result obtained with an univariate utility function by Ehrlich and Becker (1972). When we introduce the utility of amenity value, this conclusion is not always validated.

To complete this result, we conduct two supplementary analyses, an illustration that we present in "Illustration" and a theoretical exercise in which we assume, in line with much of the related literature (Drèze and Schokkaert 2013), that preferences are separable between both utility arguments, i.e., $U(C, M)=f(C)+g(M)$. The function $f(C)$ captures the effect of consumption on utility, whereas the function $g(M)$ captures the effect of forest amenity value on utility. We assume $f$ and $g$ to be continuously differentiable and strictly concave, i.e., $f^{\prime}>0, f^{\prime \prime}<0, g^{\prime}>0$, $g^{\prime \prime}<0$. In such a context, we obtain Proposition 5. The proof is in Appendix 6 .

Proposition 5 In case of unfair insurance premium, if $U_{12}=0$ and $\lambda \leq \lambda_{0}$ where $\lambda_{0}>0$, insurance and self-insurance are substitutes. Otherwise, the result concerning the substitution between insurance and self-insurance is ambiguous.

Consequently, under the simplifying assumption of a separable utility for consumption and amenity value of the forest, insurance and self-insurance are substitutes if the loading factor is inferior or equal to a threshold loading rate. This means that under some reasonable assumptions concerning the cost of insurance, we obtain the same result as Ehrlich and Becker (1972).

\section{Illustration}

We calibrate the model to represent the behavior of a representative NIPF owner whose forest stand is composed of maritime pine and located in Southwestern France $^{3}$. Such a stand is exposed to a fire risk occurring with a probability $p$ of $0.2 \%$ (Brunette et al. 2013). We assume that $R$ corresponds to the land expected value of such a stand and then, following Brunette and Caurla (2016), $R=1166.91 € /$ ha.

Following Amacher et al. (2018), the utility function is assumed to be of the form $U(C, M)=C^{\gamma} M^{1-\gamma}$ with $0<\gamma<1$. Thus, $1-\gamma$ represents the weight that forest owner gives to amenities in the utility function. Note that such a function has the following properties: $U_{1}>0, U_{11}<0, U_{2}>0, U_{22}<0, U_{12}>0$. This means that the forest owner is risk averse as regard to both arguments of the utility function, and that $\mathrm{s} /$ he has a preference for the correlation since the cross derivative is positive.

Due to the absence of information in the literature, the other parameters are calibrated with the help of forest experts. Table 2 presents the selected functions

\footnotetext{
${ }^{3}$ We focus on this case study because substantial information exists in the literature for the parametrization of the model. Moreover, maritime pine is one of the most common species in this area.
} 
Table 2 Functional forms and base values of parameters used in the illustration

\begin{tabular}{lll}
\hline Type & Function/parameter & Assumed form/value \\
\hline Utility & $U(C, M)$ & $C^{\gamma} M^{1-\gamma}$ \\
Loss & $x(q)$ & $x^{q}$ \\
Weight to amenities & $\gamma$ & 0.5 \\
Probability of fire occurrence & $p$ & 0.002 \\
Lost proportion of the revenue & $x$ & 0.5 \\
Loading factor & $\lambda$ & 0.1 \\
Annual revenue (€/ha) & $R$ & 1166.91 \\
Loss of amenities & $h=1 / 3 R$ & 388.97 \\
Amenity value & $M$ & 1166.91 \\
Unit cost of self-insurance & $c_{S I}$ & 1 \\
\hline
\end{tabular}

and describes the values used to solve the problem in the benchmark case for the illustration.

Our primary interest in conducting an illustration is to verify our theoretical results. Recall that the utility function considered for the application is such that $U_{12}>0$. The optimal decisions of risk management activities for the benchmark case are the following ones. First, in the case of fair insurance alone, the optimal insurance demand ${ }^{4}$ is equal to $\alpha^{*}=0.3$. This result confirms Proposition 1 indicating that when the insurance premium is fair, then the optimal demand corresponds to partial insurance. When the insurance premium is unfair, the optimal insurance demand is $\alpha^{*}=0.1$. This result supports Proposition 2 which predicts that full insurance is never optimal in case of unfair premium. With both insurance and selfinsurance, the optimal decisions are the couple of solutions ( 0.3 for insurance; 1 for self-insurance) under fair insurance, and ( 0.1 for insurance; 1 for self-insurance) under unfair insurance. These results support Proposition 3. They also reveal that insurance and self-insurance are complement.

Another interest for this application is that the selected specification of the utility function allows us to study the role of the weight given to consumption $\gamma$ and amenities $1-\gamma$ on optimal risk management activities. Table 3 presents how insurance and/or self-insurance demands evolve for $\gamma$ varying between 0.1 and 0.9 .

Our results highlight that for unfair insurance, in all cases, optimal risk management activities are always independent from the weight given to amenities. A change in $\gamma$ never impacts optimal decisions. As insurance is fair, due to risk aversion, the forest owner selects the optimal insurance level independently of the weight given to amenities. Contrary, for unfair insurance, the higher the weight given to amenities (and then the lesser the weight given to consumption), the lower the insurance demand. This result is still true when considering both unfair insurance and self-insurance.

\footnotetext{
${ }^{4}$ These results appear in Table 3 for $\gamma=0.5$.
} 
Table 3 Impact of the weight given to amenities on the optimal insurance and/or self-insurance

\begin{tabular}{llllll}
\hline $\begin{array}{l}\text { Weight } \\
\gamma\end{array}$ & $\begin{array}{l}\text { Fair } \\
\text { insurance }\end{array}$ & $\begin{array}{l}\text { Unfair } \\
\text { insurance }\end{array}$ & Self-insurance & $\begin{array}{l}\text { Fair insurance and } \\
\text { self-insurance }\end{array}$ & $\begin{array}{l}\text { Unfair insurance and } \\
\text { self-insurance }\end{array}$ \\
\hline 0.1 & 0.3 & 0.2 & 1 & $(0.3 ; 1)$ & $(0.2 ; 1)$ \\
0.2 & 0.3 & 0.2 & 1 & $(0.3 ; 1)$ & $(0.2 ; 1)$ \\
0.3 & 0.3 & 0.2 & 1 & $(0.3 ; 1)$ & $(0.2 ; 1)$ \\
0.4 & 0.3 & 0.1 & 1 & $(0.3 ; 1)$ & $(0.1 ; 1)$ \\
0.5 & 0.3 & 0.1 & 1 & $(0.3 ; 1)$ & $(0.1 ; 1)$ \\
0.6 & 0.3 & 0.1 & 1 & $(0.3 ; 1)$ & $(0.1 ; 1)$ \\
0.7 & 0.3 & 0 & 1 & $(0.3 ; 1)$ & $(0 ; 1)$ \\
0.8 & 0.3 & 0 & 1 & $(0.3 ; 1)$ & $(0 ; 1)$ \\
0.9 & 0.3 & 0 & 1 & $(0.3 ; 1)$ & $(0 ; 1)$ \\
\hline
\end{tabular}

The implications of the illustration results are strong. First, in the case of unfair insurance, the optimal risk management activities depend crucially on the weights given to consumption and amenities. Second, while Proposition 5 indicates that in case of separability of the utility function (and for a loading rate inferior or equal to a threshold), insurance and self-insurance are substitutes, our empirical results indicate the opposite conclusion for a non-separable bivariate utility function. This means that the traditional assumption of a separable bivariate utility function may be not adequate and may bias the representation of individual's behavior. Third, optimal risk management activity choices depend on the weight given to amenities when the insurance premium is unfair, so that it may be important to evaluate empirically this parameter $\gamma$ for private forest owners. Researches should be conducted in this direction.

\section{Discussion}

We will now summarize the results of Propositions 1,2, and 3 concerning the optimal insurance demand under fair premium, unfair premium, and self-insurance activity, respectively, and then we discuss them (see Table 4).

We found that the variation of the marginal utility of wealth with respect to the non-pecuniary variable plays a crucial role. Following Eeckhoudt et al. (2007) and Tabo (2013), the preference for the correlation $\left(U_{12} \geq 0\right)$ is the more intuitive assumption regarding the sign of the cross derivative. This means that the marginal utility of consumption increases with the amenity value of the forest. For example, a forest owner may consider that the forest should provide a way of subsistence but also leisure activities. For this owner, wood production and amenity production are complements, and then the owner expresses a preference for the correlation. This assumption is in accordance with the forest economics literature showing that NIPF owners confer commercial value to their forests but also amenity value (Newman and Wear 1993; Zhang et al. 2005). 
Table 4 Optimal decisions depending on the hypothesis on $U_{12}$

\begin{tabular}{llll}
\hline & $\begin{array}{l}\text { Optimal insurance } \\
\text { with fair premium }\end{array}$ & $\begin{array}{l}\text { Optimal insurance } \\
\text { with unfair premium }\end{array}$ & $\begin{array}{l}\text { Optimal insurance } \\
\text { with self-insurance }\end{array}$ \\
\hline$U_{12}<0$ & $\alpha^{*}>1$ & If $\lambda \leq \lambda_{0}$ where $\lambda_{0}>0, \alpha^{*}=1$ & $\begin{array}{l}\text { If } \lambda \leq \lambda_{1} \text { where } \lambda_{1}>0, \alpha^{*}=1 \\
U_{12}=0\end{array} \alpha^{*}=1$ \\
$U_{12}>0$ & $\alpha^{*}<1$ & If $\lambda \leq \lambda_{0}$ where $\lambda_{0}>0, \alpha^{*}=1$ & $\begin{array}{l}\text { If } \lambda \leq \lambda_{1} \text { where } \lambda_{1}>0, \alpha^{*}=1 \\
\alpha^{*}<1\end{array}$ \\
\hline
\end{tabular}

Under this assumption, our results reveal that full insurance is never optimal even in case of fair premium. This means that the amenity value leads the owner to reduce insurance demand, as regards to the univariate utility case, when the premium is fair. When the premium is unfair, our result is identical to the existing one with univariate utility function, i.e., partial insurance. In addition, the illustration indicates that the higher the weight given to amenities is, the lower the insurance demand will be.

An implication of this result is that, when considering amenity value, it is necessary to reduce the cost of insurance for the forest owner in order to maintain or increase his or her insurance demand. Then, amenities appear as a potential vector for public policy intervention. Indeed, at this time, some governments provide financial aid to NIPF owners after a disaster through public programs, which acts as a disincentive to owners to adopt insurance and self-insurance (Brunette and Couture 2008a, b). The explicit integration of amenities into insurance contracts may justify and redirect public intervention through insurance premium subsidies for example.

\section{Conclusion}

In this paper, we consider a bivariate utility function with consumption as the first argument and forest amenity value as the second one. We analyze optimal insurance and/or self-insurance decisions in such a framework and we compare our results with the existing ones in the literature. We find that some results depend on the cross derivative of the utility function, as ever revealed in the health economics field (Rey 2003; Eeckhoudt et al. 2007; Etner and Spaeter 2012). In particular, we show that under fair premium, full insurance is optimal only if this cross derivative is equal to zero; otherwise, under-insurance and over-insurance may be optimal. Under a positive loading factor, partial insurance is optimal only if the cross derivative is positive; otherwise, full insurance may be optimal even with an unfair insurance premium. Consequently, under certain assumptions on the cross derivative of the utility function, the Mossin's widely recognized theorem is extended to a bivariate utility model. We also observe that risk aversion increases the levels of optimal insurance demand and self-insurance activity, extending this standard result obtained with a univariate utility function to a bivariate utility function. In addition, an increase in the loss of the amenity value in the case of risk occurrence increases both the optimal insurance decision and the self-insurance one. We also analyze the potential substitutability/complementarity between the two risk management strategies 
considered. We prove that when the forest owner can simultaneously insure and invest in self-insurance activities, full insurance is never optimal if the cross derivative is positive. We also show that insurance and self-insurance may be substitutes, and if preferences are separable and the cost of insurance is not so high, then insurance and self-insurance are always considered as substitutes. However, the results of our illustration reveal a complementarity between the two coverage mechanisms, highlighting the interest to assume a non-separable bivariate utility function to adequately represent the forest owner's behavior.

Several limits or extensions of this paper should be underlined. First, we simplify our analysis by assuming two states of nature-either the natural hazard occurs or does not occur-whereas Brunette and Couture (2008a, b) indicated that an infinite number of states of nature appeared relevant for such a model. However, they proved that the results of Mossin (1968) under an infinite number of states of nature remain valid. In such a case, our simplification seems to have no impact on our results. Second, Proposition 5 is based on restrictive assumptions of separable utility for consumption and the amenity value of the forest. However, the illustration brings light on this point. Third, we assume both an exogenous amenity value for the forest and an exogenous loss of amenity value in the case of risk occurrence. Several extensions may be considered concerning these two variables. We can easily imagine that they are a function of the standing volume, for example, as is usually the case in the literature (Max and Lehman 1988). Finally, the paper is developed within a context of risk, whereas ambiguity, i.e., uncertainty about the probabilities, is increasingly relevant in a context of climate change. In addition, some evidence indicates that ambiguity has a net impact on insurance behavior (Kunreuther et al. 1995; Cabantous et al. 2011). Modeling insurance decisions under ambiguity is an emerging research field with the works of Alary et al. (2013) and Brunette et al. (2013) which consider a univariate utility function, and with the study of Etner and Spaeter (2012) who use a bivariate utility function in the field of health economics. Since self-insurance under ambiguity has not yet been analyzed, the link between insurance and self-insurance under ambiguity could therefore be an issue.

Acknowledgements This paper has been presented at the "Journées de Microéconomie Appliquée" (Clermont-Ferrand, June 2014) and at the International Conference on Economic and Financial Risks (Niort, June 2014). We are grateful to Jean-Louis Combes and Henri Loubergé for their valuable comments and to the participants of these two conferences for interesting discussions. The UMR BETA is supported by a grant from the French National Research Agency (ANR) as part of the "Investissements d'Avenir" program (ANR-11-LABX-0002-01), ARBRE Lab of Excellence.

Funding information This work was supported by the project FORWIND (ANR-12-AGRO-0007).

\section{Appendix A: Proof of Proposition 1}

Evaluating the first-order condition (4) for full insurance $(\alpha=1)$, we obtain:

$$
\left.\frac{d U(\alpha)}{d \alpha}\right|_{\alpha=1}=p(1-p) x R\left[U_{1}(R-p x R, M-h)-U_{1}(R-p x R, M)\right]
$$


Since $p(1-p) x R>0$, the sign of this expression depends on the sign of $U_{12}$ :

- If $U_{12}<0$, then $U_{1}(R-p x R, M-h)>U_{1}(R-p x R, M)$ and $\left.\frac{d U(\alpha)}{d \alpha}\right|_{\alpha=1}>0$. We deduce that $\alpha^{*}>1$.

- If $U_{12}=0$, then $U_{1}(R-p x R, M-h)=U_{1}(R-p x R, M)$ and $\left.\frac{d U(\alpha)}{d \alpha}\right|_{\alpha=1}=0$. We deduce that $\alpha^{*}=1$.

- If $U_{12}>0$, then $U_{1}(R-p x R, M-h)<U_{1}(R-p x R, M)$ and $\left.\frac{d U(\alpha)}{d \alpha}\right|_{\alpha=1}<0$. We deduce that $\alpha^{*}<1$.

\section{Appendix 2: Proof of Proposition 2}

Evaluating the first-order condition (5) for full insurance $(\alpha=1)$, we obtain:

$$
\begin{aligned}
\left.\frac{d V(\alpha)}{d \alpha}\right|_{\alpha=1}= & \operatorname{pxR}(1-(1+\lambda) p) U_{1}(R-(1+\lambda) \operatorname{px} R, M-h)-p x R((1+\lambda) \\
& -(1+\lambda) p) U_{1}(R-(1+\lambda) p x R, M)
\end{aligned}
$$

- If $U_{12} \leq 0$, then, $U_{1}(R-(1+\lambda) p x R, M-h)>U_{1}(R-(1+\lambda) p x R, M)$. Therefore, a $\lambda_{0}$ exists so that: $\left.\frac{d V(\alpha)}{d \alpha}\right|_{\alpha=1}=0$. $\lambda_{0}$ is defined as: $\operatorname{px} R(1-(1+$ ג)p $U_{1}(R-(1+\lambda) p x R, M-h)=\operatorname{px} R((1+\lambda)-(1+\lambda) p) U_{1}(R-(1+$ $\lambda) \operatorname{px} R, M)$. Then, for all $\lambda \leq \lambda_{0},\left.\frac{d V(\alpha)}{d \alpha}\right|_{\alpha=1} \geq 0$. Full insurance is always optimal.

- If $U_{12}>0$, then $U_{1}(R-(1+\lambda) p x R, M-h)<U_{1}(R-(1+\lambda) p x R, M)$, and since $\operatorname{px} R(1-(1+\lambda) p)<\operatorname{px} R((1+\lambda)-(1+\lambda) p)$, then $\left.\frac{d V(\alpha)}{d \alpha}\right|_{\alpha=1}$ is always negative. Full insurance is never optimal.

\section{Appendix 3: Impact of an increase in the loss of the forest amenity value}

\subsection{Fair insurance premium}

By differentiating the condition (4), we obtain that:

$$
\frac{d \alpha^{*}}{d h}=-\frac{\partial(\partial U(\alpha) / \partial \alpha) / \partial h}{\partial^{2} U(\alpha) / \partial \alpha^{2}}
$$

$\partial^{2} U(\alpha) / \partial \alpha^{2}$ is the second-order condition and is negative. The sign of $\frac{d \alpha^{*}}{d h}$ is the same as the sign of $\partial(\partial U(\alpha) / \partial \alpha) / \partial h$.

$$
\partial(\partial U(\alpha) / \partial \alpha) / \partial h=-p U_{12}(R-x R+\alpha x R-\alpha p x R, M-h)((1-p) x R)
$$

Since $(1-p) x R>0$, the sign of this expression depends on the sign of $U_{12}$. It is immediate to have:

- If $U_{12}<0$, then $\frac{d \alpha^{*}}{d h}>0$.

- If $U_{12}=0$, then $\frac{d \alpha^{*}}{d h}=0$.

- If $U_{12}>0$, then $\frac{d \alpha^{*}}{d h}<0$. 


\subsection{Unfair insurance premium}

By differentiating the condition (5), we obtain that:

$$
\frac{d \alpha^{*}}{d h}=-\frac{\partial(\partial V(\alpha) / \partial \alpha) / \partial h}{\partial^{2} V(\alpha) / \partial \alpha^{2}}
$$

$\partial^{2} V(\alpha) / \partial \alpha^{2}$ is the second-order condition and is negative. The sign of $\frac{d \alpha^{*}}{d h}$ is the same as the sign of $\partial(\partial V(\alpha) / \partial \alpha) / \partial h$.

$\partial(\partial V(\alpha) / \partial \alpha) / \partial h=-p U_{12}(R-x R+\alpha x R-(1+\lambda) \alpha p x R, M-h)(x R-(1-\lambda) p x R)$

As $x R-(1-\lambda) p x R>0$, the sign of this expression depends on the sign of $U_{12}$.

- If $U_{12}<0$, then $\partial(\partial V(\alpha) / \partial \alpha) / \partial h>0$.

- If $U_{12}=0$, then $\partial(\partial V(\alpha) / \partial \alpha) / \partial h=0$.

- If $U_{12}>0$, then $\partial(\partial V(\alpha) / \partial \alpha) / \partial h<0$.

\subsection{Self-insurance}

By differentiating the condition (7), we obtain:

$$
\frac{d q^{*}}{d h}=-\frac{\partial(\partial W(q) / \partial q) / \partial h}{\partial^{2} W(q) / \partial q^{2}}
$$

$\partial^{2} W(q) / \partial q^{2}$ is the second-order condition and is negative. The sign of $\frac{d q^{*}}{d h}$ is the same as the sign of $\partial(\partial W(q) / \partial q) / \partial h$.

$$
\partial(\partial W(q) / \partial q) / \partial h=p U_{12}\left(R-x(q) R-c_{S I} q, M-h\right)\left(x_{q} R+c_{S I}\right)
$$

At the optimal self-insurance level, it is necessary that $x_{q} R+c_{S I}<0$, i.e., the potential marginal benefit must be at least as high as the cost of the increase in $q$, so that the sign of this last expression depends on the sign of $U_{12}$ :

- If $U_{12}<0$, then $\partial(\partial W(q) / \partial q) / \partial h>0$.

- If $U_{12}=0$, then $\partial(\partial W(q) / \partial q) / \partial h=0$.

- If $U_{12}>0$, then $\partial(\partial W(q) / \partial q) / \partial h<0$.

\section{Appendix 4: Impact of an increase in risk aversion}

\subsection{Optimal insurance}

Let us consider a change of utility function from $U$ to $\bar{U}$. Suppose that there is an increasing and concave function $g$ such that $\bar{U}=g(U)$.

The optimal level of insurance, $\overline{\alpha^{*}}$, for the forest owner with the $\bar{U}$ utility function satisfies:

$$
\begin{aligned}
& p g^{\prime}\left(U\left(C_{L}, M-h\right)\right) U_{1}\left(C_{L}, M-h\right)(x R-(1+\lambda) p x R) \\
& \quad-(1-p) g^{\prime}\left(U\left(C_{N L}, M\right)\right) U_{1}\left(C_{N L}, M\right)((1+\lambda) p x R)=0
\end{aligned}
$$


where $C_{L}=R-x R+\overline{\alpha^{*}} x R-(1+\lambda) \overline{\alpha^{*}} p x R$ is the optimal consumption in case of loss occurrence, and $C_{N L}=R-(1+\lambda) \overline{\alpha^{*}}$ px $R$ corresponds to optimal consumption in case of no loss occurrence.

Since $g^{\prime \prime}<0$, we have $g^{\prime}\left(U\left(C_{L}, M-h\right)\right)>g^{\prime}\left(U\left(C_{N L}, M\right)\right)$. Using condition (5), it therefore follows that condition (10) will be positive when evaluated at $\alpha^{*}$. Consequently, the optimal level of insurance under $\bar{U}$ exceeds the optimal level of insurance under $U, \overline{\alpha^{*}}>\alpha^{*}$.

\subsection{Optimal self-insurance}

Let us consider a change of utility function from $W$ to $\bar{W}$. Suppose that there is an increasing and concave function $g$ such that $\bar{W}=g(W)$.

The optimal level of self-insurance activity, $\overline{q^{*}}$, for the forest owner with the $\bar{W}$ utility function satisfies:

$-p \overline{W_{1}}\left(R-x(\hat{q}) R-c_{S I} \overline{q^{*}}, M-h\right)\left(x_{q} R+c_{S I}\right)-(1-p) c_{S I} \overline{W_{1}}\left(R-c_{S I} \overline{q^{*}}, M\right)=0$

Since $g^{\prime \prime}<0$, we have $g^{\prime}\left(W\left(R-x(q) R-c_{S I} q, M-h\right)\right)>g^{\prime}\left(W\left(R-c_{S I} q, M\right)\right)$. Using condition (7), it therefore follows that condition (11) will be positive when evaluated at $q^{*}$. Consequently, the optimal level of self-insurance under $\bar{W}$ exceeds the optimal level of self-insurance under $U, \overline{q^{*}}>q^{*}$.

\section{Appendix 5: Proof of Proposition 4}

The expected utility maximization problem is reproduced here as:

$$
\begin{aligned}
V(\alpha, q)= & p U\left(R-x(q) R+\alpha x(q) R-(1+\lambda) \alpha p x(q) R-c_{S I} q, M-h\right) \\
& +(1-p) U\left(R-(1+\lambda) \alpha p x(q) R-c_{S I} q, M\right)
\end{aligned}
$$

The optimal levels of insurance and self-insurance are defined by the following firstorder conditions:

$$
\begin{gathered}
\left.V_{\alpha}=\frac{\partial V(\alpha, q)}{\partial \alpha}=p U_{1}\left(C_{L}, M-h\right)(x(q) R-(1+\lambda) p x(q) R)\right) \\
-(1-p) U_{1}\left(C_{N L}, M\right)((1+\lambda) p x(q) R)=0 \\
V_{q}=\frac{\partial V(\alpha, q)}{\partial q}=p U_{1}\left(C_{L}, M-h\right)\left(-x_{q} R+\alpha x_{q} R-(1+\lambda) \alpha p x_{q} R-c_{S I}\right) \\
-(1-p) U_{1}\left(C_{N L}, M\right)\left((1+\lambda) \alpha p x_{q} R+c_{S I}\right)=0
\end{gathered}
$$

with $C_{L}=R-x(q) R+\alpha x(q) R-(1+\lambda) \alpha p x(q) R-c_{S I} q$ and $C_{N L}=R-(1+$ $\lambda) \alpha \operatorname{px}(q) R-c_{S I} q$.

The second-order conditions are the following ones:

$$
\begin{gathered}
\left.V_{\alpha \alpha}=p U_{11}\left(C_{L}, M-h\right)(x(q) R-(1+\lambda) p x(q) R)\right)^{2} \\
-(1-p) U_{11}\left(C_{N L}, M\right)((1+\lambda) p x(q) R)^{2}<0 \\
V_{q q}=p U_{11}\left(C_{L}, M-h\right)\left(-x_{q} R+\alpha x_{q} R-(1+\lambda) \alpha p x_{q} R-c_{S I}\right)^{2} \\
-(1-p) U_{11}\left(C_{N L}, M\right)\left((1+\lambda) \alpha p x_{q} R+c_{S I}\right)^{2}
\end{gathered}
$$




$$
\begin{aligned}
& +p U_{1}\left(C_{L}, M-h\right)\left(-x_{q q} R+\alpha x_{q q} R-(1+\lambda) \alpha p x_{q q} R\right) \\
& -(1-p) U_{1}\left(C_{N L}, M\right)\left((1+\lambda) \alpha p x_{q q} R\right)<0
\end{aligned}
$$

These two second-order conditions hold due to our assumptions.

The matrix of the second-order conditions is:

$$
\left[\begin{array}{ll}
V_{\alpha \alpha} & V_{\alpha q} \\
V_{q \alpha} & V_{q q}
\end{array}\right]
$$

with

$$
\begin{gathered}
V_{\alpha q}=p U_{1}\left(C_{L}, M-h\right)\left(x_{q} R-(1+\lambda) p x_{q} R\right)-(1-p) U_{1}\left(C_{N L}, M\right)\left((1+\lambda) p x_{q} R\right) \\
+p U_{11}\left(C_{L}, M-h\right)\left(-x_{q} R+\alpha x_{q} R-(1+\lambda) \alpha p x_{q} R-c_{S I}\right)\left(x_{q} R-(1+\lambda) p x_{q} R\right) \\
+(1-p) U_{11}\left(C_{N L}, M\right)\left((1+\lambda) \alpha p x_{q} R+c_{S I}\right)(1+\lambda) p x_{q} R
\end{gathered}
$$

The determinant of the matrix $\Delta$ is negative.

To obtain how self-insurance and insurance vary as a parameter changes, we apply the Cramer's rule and we find that:

$$
\left[\begin{array}{ll}
V_{\alpha \alpha} & V_{\alpha q} \\
V_{q \alpha} & V_{q q}
\end{array}\right]\left[\begin{array}{l}
d \alpha^{*} \\
d q^{*}
\end{array}\right]=-\left[\begin{array}{ll}
V_{\alpha c_{S I}} & V_{\alpha \lambda} \\
V_{q c_{S I}} & V_{q \lambda}
\end{array}\right]\left[\begin{array}{l}
d c_{S I} \\
d \lambda
\end{array}\right]
$$

Using this principle, we have:

$$
\begin{aligned}
\frac{d \alpha^{*}}{d c_{S I}} & =-\frac{1}{\Delta}\left[\begin{array}{cc}
V_{\alpha c_{S I}} & V_{\alpha q} \\
V_{q c_{S I}} & V_{q q}
\end{array}\right] \\
\frac{d q^{*}}{d \lambda} & =-\frac{1}{\Delta}\left[\begin{array}{ll}
V_{\alpha \alpha} & V_{\alpha \lambda} \\
V_{q \alpha} & V_{q \lambda}
\end{array}\right]
\end{aligned}
$$

The details of these two expressions are available from the authors upon request. After simplifications, the signs of these two expressions are obtained as ambiguous.

\section{Appendix 6: Proof of Proposition 5}

Under the assumption of a separable utility function, the forest owner's objective is:

$$
\begin{aligned}
V_{s}(\alpha, q) & =p f(R-x(q) R+\alpha x(q) R-(1+\lambda) \alpha p x(q) R-c q)+p g(M-h) \\
& +(1-p) f(R-(1+\lambda) \alpha p x(q) R-c q)+(1-p) g(M)
\end{aligned}
$$

The first-order conditions defining optimal insurance, $\alpha_{s}^{*}$, and self-insurance, $q_{s}^{*}$, are:

$$
\begin{gathered}
\left.\frac{\partial V_{s}(\alpha, q)}{\partial \alpha}=p f^{\prime}\left(C_{L}\right)\left(x\left(q_{s}^{*}\right) R-(1+\lambda) p x\left(q_{s}^{*}\right) R\right)\right) \\
-(1-p) f^{\prime}\left(C_{N L}\right)\left((1+\lambda) p x\left(q_{s}^{*}\right) R\right)=0 \\
\frac{\partial V_{s}(\alpha, q)}{\partial q}=p f^{\prime}\left(C_{L}\right)\left(-x_{q} R+\alpha_{s}^{*} x_{q} R-(1+\lambda) \alpha p x_{q} R-c_{S I}\right) \\
-(1-p) f^{\prime}\left(C_{N L}\right)\left((1+\lambda) \alpha_{s}^{*} p x_{q} R+c_{S I}\right)=0
\end{gathered}
$$


with $C_{L}=R-x\left(q_{s}^{*}\right) R+\alpha_{s}^{*} x\left(q_{s}^{*}\right) R-(1+\lambda) \alpha_{s}^{*} p x\left(q_{s}^{*}\right) R-c_{S I} q_{s}^{*}$, and $C_{N L}=R-(1+\lambda) \alpha_{s}^{*} p x\left(q_{s}^{*}\right) R-c_{S I} q_{s}^{*}$.

We analyze the impact of a variation of $c_{S I}$ on optimal insurance $\alpha^{*}$. Using the same principle presented in Proposition 4, we have:

$$
\frac{d \alpha^{*}}{d c_{S I}}=-\frac{1}{\Delta}\left[\begin{array}{ll}
V_{\alpha c_{S I}} & V_{\alpha q} \\
V_{q c_{S I}} & V_{q q}
\end{array}\right]
$$

Initially, we try to obtain the signs of each element of the matrix. By second-order conditions, we have $V_{q q}<0$.

After simplifications, and using first-order conditions, and the definition of the absolute risk aversion coefficient, $A R(C)=-\frac{f^{\prime \prime}(C)}{f^{\prime}(C)}$, we obtain:

$$
V_{\alpha c_{S I}}=\frac{(1+\lambda) p x(q) R q(1-p)}{f^{\prime}\left(C_{N L}\right)}\left(A R\left(C_{L}\right)-A R\left(C_{N L}\right)\right)
$$

Assuming that preferences exhibit decreasing absolute risk aversion (DARA), then $A R\left(C_{L}\right) \geq A R\left(C_{N L}\right)$, and then $V_{\alpha c_{S I}} \geq 0$.

We also obtain:

$$
\begin{aligned}
V_{q c_{S I}}= & -p f^{\prime}\left(C_{L}\right)-(1-p) f^{\prime}\left(C_{N L}\right) \\
& +\frac{\left((1+\lambda) \alpha p x_{q} R+c\right) q(1-p)}{f^{\prime}\left(C_{N L}\right)}\left(A R\left(C_{L}\right)-A R\left(C_{N L}\right)\right)
\end{aligned}
$$

Under DARA and $\left((1+\lambda) \alpha p x_{q} R+c\right)<0$, the marginal benefit of self-insurance is greater than the marginal cost, $V_{q c_{S I}}<0$.

$$
\begin{aligned}
V_{\alpha q}= & p x_{q} R(1-(1+\lambda) p)\left(f^{\prime}\left(C_{L}\right)-(1+\lambda) f^{\prime}\left(C_{N L}\right)\right. \\
& +\frac{\left((1+\lambda) \alpha p x_{q} R+c\right)(1+\lambda) p x(q) R(1-p)}{f^{\prime}\left(C_{N L}\right)} \\
& \left(-\frac{(1-p)}{p} \frac{f^{\prime}\left(C_{N L}\right)}{f^{\prime}\left(C_{L}\right)} A R\left(C_{L}\right)-A R\left(C_{N L}\right)\right)
\end{aligned}
$$

The sign of $V_{\alpha q}$ is ambiguous under our initial conditions. Therefore, the sign of $\frac{d \alpha^{*}}{d c_{S I}}$ is ambiguous.

As found in Proposition 2, we know that, in case of unfair insurance premium, for $\lambda \leq \lambda_{0}$, full insurance is optimal. In this context, we analyze different cases concerning the level of loading rate: fair insurance $(\lambda=0)$ and unfair insurance with $\lambda \leq \lambda_{0}$ or $\lambda>\lambda_{0}$ :

- Fair insurance: $\lambda=0$

In this case, we have $\alpha^{*}=1$ and $q^{*}=0$. We have:

$$
\frac{d \alpha^{*}}{d c_{S I}}=-\frac{1}{\Delta}\left[\begin{array}{ll}
0 & 0 \\
-f^{\prime}\left(C_{N L}\right) & V_{q q}
\end{array}\right]=0
$$

- Unfair insurance: $\lambda>0$ and $\lambda \leq \lambda_{0}$

In this case, we have $\alpha^{*}=1$ and we have:

$$
\frac{d \alpha^{*}}{d c_{S I}}=-\frac{1}{\Delta}\left[\begin{array}{ll}
0 & -\lambda p x_{q} f^{\prime}\left(C_{N L}\right) \\
-f^{\prime}\left(C_{N L}\right) & V_{q q}
\end{array}\right]>0
$$


- Unfair insurance: $\lambda>0$ and $\lambda>\lambda_{0}$

In this case, we have $\alpha^{*}<1$. We obtain that, under DARA and $\left((1+\lambda) \alpha p x_{q} R+\right.$ $c)<0, V_{q c_{S I}}<0$, and under DARA, $V_{\alpha c_{S I}} \geq 0$. We also have $V_{q q}<0$ but the sign of $V_{\alpha q}$ is ambiguous. Finally, in this case, the sign of $\frac{d \alpha^{*}}{d c_{S I}}$ is ambiguous.

\section{References}

Alary, D., Gollier, C., Treich, N. (2013). The effect of ambiguity aversion on insurance and self-protection. The Economic Journal, 123(573), 1188-1202.

Amacher, G.S., Ollikainen, M., Koskela, E. (2009). Economics offorest resources. Cambridge: MIT Press.

Amacher, G.S., Ollikainen, M., Puhakka, M. (2018). Renewable resource use and nonseparable amenity benefits. Environmental and Resource Economics, 69(4), 637-659.

Andersson, M., \& Gong, P. (2010). Risk preferences, risk perceptions and timber harvest decisions an empirical study of nonindustrial private forest owners in northern Sweden. Forest Policy and Economics, 12(5), 330-339.

Arrow, K. (1963). Uncertainty and the welfare economics of medical care. American Economic Review, 53(5), 941-973.

Brunette, M., \& Caurla, S. (2016). An economic comparison of risk handling measures against Hylobius abietis and Heterobasidion annosum in the Landes de Gascogne forest. Annals of Forest Science, 70(3), 777-787.

Brunette, M., \& Couture, S. (2008a). Public compensation for windstorm damage reduces incentives for risk management investments. Forest Policy and Economics, 10(7-8), 491-499.

Brunette, M., \& Couture, S. (2008b). Assurance et activités de réduction des risques en foresterie : Une approche théorique. Revue d'Études en Agriculture et Environnement, 86(1), 57-78.

Brunette, M., \& Couture, S. (2013). Risk management behaviour of a forest owner to address growth risk. Agricultural and Resource Economics Review, 42(2), 349-364.

Brunette, M., Cabantous, L., Couture, S., Stenger, A. (2013). The impact of governmental assistance on insurance demand under ambiguity: a theoretical model and an experimental test. Theory and Decision, 75(2), 153-174.

Brunette, M., Foncel, J., Kéré, E. (2017). Attitude towards risk and production decision: an empirical analysis on French private forest owners. Environmental Modeling and Assessment, 22(6), 563-576.

Cabantous, L., Hilton, D., Kunreuther, H., Michel-Kerjan, E. (2011). Is imprecise knowledge better than conflicting expertise? Evidence from insurers' decisions in the United States. Journal of Risk and Uncertainty, 42(3), 211-232.

Cook, P.J., \& Graham, D.A. (1977). The demand for insurance and protection: the case of irreplaceable commodities. The Quarterly Journal of Economics, 91(1), 143-156.

Denuit, M., Eeckhoudt, L., Menegatti, M. (2011). Correlated risks, bivariate utility and optimal choices. Economic Theory, 46(1), 39-54.

Dionne, G., \& Eeckhoudt, L. (1985). Self-insurance, self-protection and increased risk aversion. Economics Letters, 17(1-2), 39-42.

Drèze, J.H., \& Schokkaert, E. (2013). Arrow's theorem of the deductible: moral hazard and stop-loss in health insurance. Journal of Risk and Uncertainty, 47(2), 147-163.

Eeckhoudt, L., Godfroid, P., Marchand, M. (1998). Risque de santé, médecine préventive et médecine curative. Revue d'Economie Politique, 108(3), 321-337.

Eeckhoudt, L., Gollier, C., Schlesinger, H. (2005). Economics and financial decisions under risk. Princeton: Princeton University Press.

Eeckhoudt, L., Rey, B., Schlesinger, H. (2007). A good sign for multivariate risk taking. Management Science, 53(1), 117-124.

Ehrlich, I., \& Becker, G.S. (1972). Market insurance, self-insurance, and self-protection. Journal of Political Economy, 80(4), 623-648.

Eisner, R., \& Strotz, R. (1961). Flight insurance and the theory of choice. Journal of Political Economy, 69(4), 355-368.

Englin, J., Boxall, P., Hauer, G. (2000). An empirical examination of optimal rotations in a multiple use forest in the presence of fire risk. Journal of Agricultural and Resource Economics, 25(1), 14-27. 
Epstein, L.G., \& Tanny, S.M. (1980). Increasing generalized correlation: a definition and some economic consequences. Canadian Journal of Economics, 13(1), 16-34.

Etner, J., \& Spaeter, S. (2012). Self-protection and private insurance with ambiguous and non-pecuniary risks. Working Paper.

Hartman, R. (1976). The harvest decision when a standing forest has value. Economic Inquiry, 14(1), 52-58.

Holecy, J., \& Hanewinkel, M. (2006). A forest management risk insurance model and its application to coniferous stands in southwest Germany. Forest Policy and Economics, 8(2), 161-174.

Huang, R.J., \& Tzeng, L.Y. (2006). The design of an optimal insurance contract for irreplaceable commodities. The Geneva Risk and Insurance Review, 31(1), 11-21.

Kangas, J. (1994). Incorporating risk attitude into comparison of reforestation alternatives. Scandinavian Journal of Forest Research, 9(1-4), 297-304.

Koskela, E., \& Ollikainen, M. (1997). The optimal design of forest taxes with multiple use characteristics of forest stands. Environmental and Resource Economics, 10(1), 41-62.

Kunreuther, H., Meszaros, J., Hogarth, R., Spranca, M. (1995). Ambiguity and underwriter decision processes. Journal of Economic Behavior and Organization, 26(3), 337-352.

Manley, B., \& Watt, R. (2009). Forestry insurance, risk pooling and risk mitigation options. Technical report, Report prepared for MAF Project CM-09 under MAF POL 0809-11194.

Max, W., \& Lehman, D.E. (1988). A behavioral model of timber supply. Journal of Environmental Economics and Management, 15(1), 71-86.

Mossin, J. (1968). Aspects of rational insurance purchasing. Journal of Political Economy, 76(4), 553-568.

Newman, D., \& Wear, D. (1993). The production economics of private forestry: a comparison of industrial and non-industrial forest owners. American Journal of Agricultural Economics, 75(3), 674-684.

Pattanayak, S.K., Murray, B.C., Abt, R. (2002). How joint is joint forest production? an econometric analysis of timber supply conditional on endogenous amenity values. Forest Science, 47(3), 479-491.

Rey, B. (2003). A note on optimal insurance in the presence of a nonpecuniary background risk. Theory and Decision, 54(1), 73-83.

Schelhaas, M.J., Nabuurs, G.J.L., Schuck, A. (2003). Natural disturbances in the European forests in the 19th and 20th centuries. Global Change Biology, 9(11), 1620-1633.

Schlesinger, H. (1984). Optimal insurance for irreplaceable commodities. The Journal of Risk and Insurance, 51(1), 131-137.

Schlesinger, H. (2000). The theory of insurance demand. In Handbook of insurance, kluwer academic publishers(chapter 5) (pp. 131-151).

Smith, V. (1968). Optimal coverage. Journal of Political Economy, 76(1), 68-77.

Tabo, A.L. (2013). Analyse économique des comportements de prévention face aux risques de santé. thèse université Paris Ouest Nanterre La défense.

Zhang, Y., Zhang, D., Schelhaas, J. (2005). Small-scale non-industrial private forest ownership in the United States: rationale and implications for forest management. Silva Fennica, 39(3), 443-454. 